\title{
BMJ Open Obesity and sickness absence: results from a longitudinal nationally representative sample from Germany
}

\author{
Katrin Christiane Reber, Hans-Helmut König, André Hajek
}

To cite: Reber KC, König H-H, Hajek A. Obesity and sickness absence: results from a longitudinal nationally representative sample from Germany. BMJ Open 2018;8:e019839. doi:10.1136/ bmjopen-2017-019839

- Prepublication history and additional material for this paper are available online. To view these files, please visit the journal online (http://dx.doi org/10.1136/bmjopen-2017019839).

Received 9 October 2017 Revised 17 April 2018 Accepted 27 April 2018
Check for updates

Department of Health Economics and Health Services Research, University Medical Center Hamburg-Eppendorf, Hamburg, Germany

Correspondence to

Dr André Hajek; a.hajek@uke.de

\begin{abstract}
Objectives The current study aimed at investigating the longitudinal association between obesity and sickness absence in women and men in Germany.

Methods Data were derived from the German

Socio-Economic Panel (GSOEP) which is a nationally representative, longitudinal study of private households in Germany. We draw on data from 2002 to 2012. Information on self-rated body mass index has been collected every second wave since 2002. Sick leave days (total number of working days missed due to illness in the past calendar year) and sick from work for more than 6 weeks in the preceding 12 months (yes/no) were used as outcome measures. Fixed-effects $(\mathrm{FE})$ regression models were used for the total sample and stratified by sex. Gender differences were examined using interaction terms (sex $x$ weight category).

Results Controlling for several potential confounders, Poisson FE regression analysis showed that transitions from normal weight to obesity were associated with an increase in sick leave days in women (incidence rate ratio (IRR) $1.27,95 \% \mathrm{Cl} 1.02$ to 1.57 ) but not in men (IRR $0.85,95 \% \mathrm{Cl} 0.68$ to 1.06$)$-with significant gender differences (sex $\times$ obesity, $p<0.01$ ). Moreover, conditional FE logistic regressions showed that transitions from normal weight to overweight were associated with an increase in the probability of long-term absenteeism in women (overweight, $\mathrm{OR} 1.41,95 \% \mathrm{Cl} 1.08$ to 1.85 ) but not in men (overweight, $\mathrm{OR} 0.84,95 \% \mathrm{Cl} 0.65$ to 1.09 ). Gender differences were significant (sex $\times$ overweight, $p<0.01$ ). Conclusions Our findings stress the longitudinal association between excess weight and increased likelihood of sick leave days as well as long-term absenteeism in women.
\end{abstract}

\section{INTRODUCTION}

Obesity remains a major health concern in Western societies. ${ }^{1}$ Behind the Americas, Europe ranks second regarding the proportion of overweight $\left(25 \mathrm{~kg} / \mathrm{m}^{2} \leq\right.$ body mass index $(\mathrm{BMI})<30 \mathrm{~kg} / \mathrm{m}^{2}$ ) or obese (BMI $\geq 30 \mathrm{~kg}$ / $\mathrm{m}^{2}$ ) people, according to $\mathrm{WHO}$ statistics. The share of men and women being 18 years and over having a BMI $\geq 25 \mathrm{~kg} / \mathrm{m}^{2}$ amounts to $59.1 \%$ and $44.7 \%$, respectively, and in the EU-28. For Germany, the prevalence of adult obesity has recently been estimated to range

\section{Strengths and limitations of this study}

Data came from a large nationally representative sample of German individuals.

- Panel regression models were used, diminishing the problem of unobserved heterogeneity.

- The possibility of reverse causality cannot be dismissed.

- The self-rated body mass index was used to classify obesity.

between $16.5 \%$ and $23.9 \%$ in women and between $17.3 \%$ and $23.3 \%$ in men. ${ }^{23}$ Obesity and its related adverse health effects pose a considerable burden to the healthcare system because of both its direct costs incurred by increased health service utilisation and indirect costs arising from reduced or lost workforce productivity. ${ }^{45}$ Several studies found that indirect costs of overweight and obesity make up the majority $(51 \%-59 \%)$ of total costs, thus exceeding direct costs. ${ }^{6}$ Unsurprisingly, the impact of obesity on the workplace in terms of absence from work due to excess weight-related illnesses or other factors continues to be of primary interest to health policy-makers and employers.

The association between obesity and sickness absence has been well documented cross-sectionally. Studies found a tendency for obese individuals to have a higher number of sick leave events and also have longer spells of individual sick leave compared with their normal-weight counterparts. ${ }^{48}$ As regards preobesity/overweight, inconsistent results have been reported in literature for the association with sickness absence. While some studies found evidence of an elevated risk of sick leave for preobese subjects, others reported no significant association when compared with normal-weight subjects. ${ }^{7} 8$ However, in general, there tended to be a positive relationship between higher levels of BMI and sick leave, although available results pertaining to short-term spells were less clear, 
which may be due to discrepant definitions of short-term sick leave. ${ }^{7-9}$ Findings further suggested gender differences regarding the association between sickness absence and both preobesity and obesity. Women showed higher rates of sickness absence and also stronger associations were observed for female employees. ${ }^{4011}$

Many studies that have been conducted so far employ cross-sectional designs which do not allow drawing conclusions about causal mechanisms. So far, there is yet limited longitudinal research investigating the association between excess weight and sickness absence. While most of the longitudinal studies have been carried out in the USA or the Scandinavian countries, evidence is still lacking for Germany. Therefore, the aim of this study was to assess the association between obesity and sickness absence using a representative sample of the German labour force in a longitudinal setting.

\section{STUDY POPULATION AND METHODS \\ Sample}

We used data from the German Socio-Economic Panel Study (GSOEP), a representative longitudinal survey of the German population conducted on an annual basis since $1984 .^{12}$ The GSOEP is located at the German Institute for Economic Research (Deutsches Institut für Wirtschaftsforschun, Berlin). It is a household panel like the Panel Study of Income Dynamics in the USA or the British Household Panel Study. Every year, approximately 11000 households and more than 20000 individuals were interviewed. All adult household members (aged 17 and over) are interviewed. Topics include, for example, domain satisfaction (eg, satisfaction with leisure time), health or occupational status. Very high reinterview response rates were observed in the GSOEP. ${ }^{13}$ In addition, it was found that survey attrition is low in the GSOEP (in most years and subsamples, attrition was less than $10 \% .^{14}$

${ }^{15}$ Further details regarding the sampling frame as well as the survey design of the GSOEP are given elsewhere. ${ }^{16}$

In the current study, the analyses were based on data from six waves (2002-2012, biannually), because BMI was assessed only biannually. We restricted our sample to individuals aged 17-65 years who were in the labour force and employed at all waves. Thus, while regression analysis with sick leave days as outcome measure is based on 48865 observations, the regression analysis with longterm absenteeism as outcome measure is based on 9564 observations.

All information is based on self-reports obtained by respondents.

\section{Dependent variables}

Our dependent variables were sick leave days and longterm absenteeism. Sick leave days is operationalised as the total number of working days missed due to illness in the past calendar year ('How many days were you not able to work in 20XX because of illness? Please state all the days, not just those for which you had an official note from your doctor.'). Individuals reported the frequency of days of absence ('none', 'a total of X days'). Long-term absenteeism is based on a question that assessed whether a person was sick from work for more than 6 weeks at one time in the previous calendar year ('Were you sick from work for more than 6 weeks at one time last year?'). Employees who reported not being sick from work for more than 6 weeks were coded as zero, while employees with a positive answer ('yes, once' and 'yes, several times') were coded as one.

\section{Independent variables}

BMI was based on self-reported values of height and weight and calculated as weight divided by squared height $\left(\mathrm{kg} / \mathrm{m}^{2}\right)$. We categorised BMI into four groups according to WHO classification as underweight (BMI $\leq 18.5 \mathrm{~kg}$ / $\left.\mathrm{m}^{2}\right)$, normal weight $\left(18.5 \mathrm{~kg} / \mathrm{m}^{2} \leq \mathrm{BMI}<25 \mathrm{~kg} / \mathrm{m}^{2}\right)$, preobese/overweight $\left(25 \mathrm{~kg} / \mathrm{m}^{2} \leq \mathrm{BMI}<30 \mathrm{~kg} / \mathrm{m}^{2}\right)$ and obese $\left(\right.$ BMI $\left.\geq 30 \mathrm{~kg} / \mathrm{m}^{2}\right) .{ }^{17} 18$

Several sociodemographic, health-related and subjective well-being factors that have been identified by prior research to be associated with both excess weight and productivity loss, or proposed to influence the relationship between obesity and sickness absence were entered as potential confounders in the analyses. ${ }^{9} 101920$ As regards sociodemographic characteristics, we considered age and marital status, the latter being dichotomised with married, living together coded as one and zero otherwise (ie, married, but living separated from spouse; divorced; widowed; single are coded as zero). Concerning health-related and subjective well-being factors, we included subjective health, which was based on individuals' self-rated health (5-point Likert scale: $1=$ ='bad' and $5=$ ='very good') and disability assessed by a single item asking whether they were 'legally classified as handicapped or capable of gainful employment only to a reduced extent due to medical reasons' (no/yes). The disability variable served as a proxy measure for objective morbidity. ${ }^{21}{ }^{22}$ In accordance with prior research, ${ }^{23}$ the continuous variable satisfaction with life evaluated by the question 'How satisfied are you with your life, all things considered?' (11-point rating scale ranging from 0 'completely dissatisfied' to 10 'completely satisfied') was included. Moreover, the time-invariant variable sex was used for descriptive purposes.

\section{Statistical analysis}

We used fixed-effects (FE) regression models to estimate the longitudinal association between excess weight and sickness absence. As the sick leave days is a non-negative integer number (count data), the Poisson model was chosen. To analyse the longitudinal association between excess weight and the binary outcome long-term absenteeism, we employed a conditional logit FE model, which is a common method for panel data analysis. FE models permit correlations between unobserved time-invariant variables (eg, genetic disposition) and predictors, yielding consistent estimates (when the strict exogeneity assumption holds). ${ }^{24}$ 
Our main goal was to provide consistent estimates under very weak assumptions. ${ }^{24}{ }^{25}$ Therefore, FE regressions were used. The FE specification was also preferred based on the Hausman test. ${ }^{26}$ For example, the Hausman test statistic was $\mathrm{X}^{2}=838.31, \mathrm{p}<0.001$ (with sick leave days as outcome measure).

FE models solely exploit changes within units (here: participants) over time ('within variation'). Consequently, the effect of variables that are time constant (eg, sex) cannot be estimated by FE regressions. ${ }^{24}$ Yet, FE regressions do allow for interactions between time-invariant and time-varying predictors. ${ }^{25}$

Therefore, we first estimated the model for the total sample (implicitly controlling for the time-invariant variable sex). In order to explore the potential gender-related differential association with obesity, we then conducted the analysis separately for men and women. We also estimated the model, including an interaction term between BMI class and sex, which allows us to further test for and measure significant differences between male and female employees. This procedure was similar for both the FE Poisson model and the conditional logit FE model.

Models were tested for multicollinearity between predictor variables using the variance inflation factor. Yet, we could not detect a collinearity problem (ie, all variance inflation factors were below 2). For the FE Poisson regressions, cluster robust SEs were used. ${ }^{27}$

A p value less than 0.05 was deemed statistically significant. All analyses were performed using Stata V.14.2.

\section{Patient and public involvement}

No patients were directly involved in the development of the research question, selection of the outcome measures, design and implementation of the study or interpretation of the results.

\section{RESULTS}

\section{Sample characteristics}

Pooled sample characteristics for individuals included in FE regression analysis with sick leave days (column 1) and long-term absenteeism (column 2) as outcome variables are described in table 1 . Total observations differ among the models, as there was a varying number of changes over time in these outcome measures (intraindividual changes in sick leave days vs intraindividual changes in long-term absenteeism). Thus, while the Poisson FE regression (with sick leave days as outcome measure) is based on 48865 observations, the conditional $\mathrm{FE}$ logistic regression (with long-term absenteeism as outcome measure) is based on 9564 observations. It might be the case that individuals with within-variation on sick leave days also provide within-information on long-term absenteeism. However, it is not necessarily the case.

In total (table 1, columns 1 and 2), nearly one-half were female $(47.8 \%$ in the sample with sick leave days as outcome, $48.7 \%$ in the sample with long-term absenteeism as outcome). The mean age was 41.9 ( \pm 11.2 years; $17-64$ years) and $45.4( \pm 10.4$ years; $17-64$ years $)$ in the sick leave days sample and in the long-term absenteeism sample, respectively. According to $\mathrm{WHO}$ categories, $1.8 \%$ were classified as underweight, $48.1 \%$ as normal weight, $35.5 \%$ as overweight and $14.6 \%$ as obese, respectively, in the sick leave days sample. In the sample with long-term absenteeism as outcome, $1.3 \%$ were classified as underweight, $41.3 \%$ as normal weight, $38.0 \%$ as overweight and $19.4 \%$ as obese, respectively. Please see table 1 for further details.

\section{Regression analysis}

Results of Poisson FE regressions with sick leave days as outcome measure are displayed in table 2. Adjusting for potential confounders, regressions showed that transitions from normal weight to obesity were associated with

Table 1 Sample characteristics for individuals included in FE regressions for the outcomes sick leave days and long-term absenteeism (wave 2002, wave 2004, wave 2006, wave 2008, wave 2010 and wave 2012, pooled)

\begin{tabular}{|c|c|c|c|c|}
\hline & \multicolumn{2}{|c|}{ Sick leave days $(n=48865)$} & \multicolumn{2}{|c|}{ Long-term absenteeism $(n=9564)$} \\
\hline & $\mathrm{N} / \mathrm{mean}$ & $\% / S D$ & $\mathrm{~N} / \mathrm{mean}$ & $\% / S D$ \\
\hline Female & 23350 & $47.8 \%$ & 4658 & $48.7 \%$ \\
\hline Age (in years) & 41.9 & 11.2 & 45.4 & 10.4 \\
\hline Married, living together with spouse & 30016 & $61.4 \%$ & 6376 & $66.7 \%$ \\
\hline Self-rated health (from $1=$ 'very good' to $5=$ 'very bad') & 2.5 & 0.8 & 2.8 & 0.9 \\
\hline Not severely disabled & 45644 & $93.4 \%$ & 8007 & $83.7 \%$ \\
\hline Life satisfaction (from $0=$ worst to $10=$ best) & 7.1 & 1.6 & 6.7 & 1.8 \\
\hline Underweight & 867 & $1.8 \%$ & 126 & $1.3 \%$ \\
\hline Normal weight & 23524 & $48.1 \%$ & 3951 & $41.3 \%$ \\
\hline Overweight & 17327 & $35.5 \%$ & 3632 & $38.0 \%$ \\
\hline Obese & 7147 & $14.6 \%$ & 1855 & $19.4 \%$ \\
\hline
\end{tabular}

The explanatory variable sex was not included in FE regressions as independent variable, as it is time constant (ie, it usually did not vary within individuals over time). It was only used for descriptive purposes.

FE, fixed effects. 
Table 2 Results of Poisson FE regressions (wave 2002, wave 2004, wave 2006, wave 2008, wave 2010 and wave 2012)

\begin{tabular}{|c|c|c|c|c|}
\hline Independent variables & $\begin{array}{l}\text { (1) Sick leave } \\
\text { days: total sample }\end{array}$ & $\begin{array}{l}\text { (2) Sick leave } \\
\text { days: men }\end{array}$ & $\begin{array}{l}\text { (3) Sick leave } \\
\text { days: women }\end{array}$ & $\begin{array}{l}\text { (4) Sick leave } \\
\text { days: total sample } \\
\text { with interaction term }\end{array}$ \\
\hline \multirow[t]{2}{*}{ Age } & $1.02^{\star \star \star}$ & $1.02^{\star \star}$ & $1.02^{* \star *}$ & $1.02^{\star \star \star}$ \\
\hline & (1.01 to 1.03$)$ & (1.00 to 1.03$)$ & (1.01 to1.03) & (1.01 to 1.03$)$ \\
\hline $\begin{array}{l}\text { Married, living together with spouse } \\
\text { (Ref.: others) }\end{array}$ & $1.09 \dagger$ & 1.05 & $1.13 \dagger$ & $1.09 \dagger$ \\
\hline \multirow{2}{*}{$\begin{array}{l}\text { Self-rated health (from } 1=\text { very good' } \\
\text { to } 5=\text { 'bad') }\end{array}$} & $1.50^{\star \star \star}$ & $1.54^{\star \star \star}$ & $1.45^{\star * *}$ & $1.50^{\star \star *}$ \\
\hline & (1.44 to 1.56$)$ & (1.46 to 1.64$)$ & (1.38 to 1.53$)$ & (1.44 to 1.56$)$ \\
\hline $\begin{array}{l}\text { Severely disabled (Ref.: not severely } \\
\text { disabled) }\end{array}$ & $2.28^{* * *}$ & $2.19^{\star \star \star}$ & $2.37^{\star \star \star}$ & $2.27^{\star \star *}$ \\
\hline $\begin{array}{l}\text { Life satisfaction (from } 0=\text { worst to } \\
10=\text { best) }\end{array}$ & (0.92 to 0.96$)$ & (0.91 to 0.96$)$ & (0.92 to 0.97$)$ & (0.92 to 0.96$)$ \\
\hline \multirow[t]{2}{*}{ Underweight (Ref.: normal weight) } & 0.95 & 0.74 & 1.00 & 0.74 \\
\hline & $(0.73$ to 1.22$)$ & (0.36 to 1.49$)$ & (0.77 to 1.31$)$ & (0.36 to 1.52$)$ \\
\hline \multirow[t]{2}{*}{ Overweight (Ref.: normal weight) } & 1.00 & 0.92 & 1.10 & 0.91 \\
\hline & (0.91 to 1.10$)$ & (0.81 to 1.04$)$ & (0.96 to 1.25$)$ & (0.80 to 1.03$)$ \\
\hline \multirow[t]{2}{*}{ Obesity (Ref.: normal weight) } & 1.03 & 0.85 & $1.27^{*}$ & 0.83 \\
\hline & (0.88 to 1.20$)$ & (0.68 to 1.06$)$ & (1.02 to 1.57$)$ & (0.67 to 1.04$)$ \\
\hline $\begin{array}{l}\text { Interaction term: underweight } \times \text { sex } \\
\text { (Ref. male) }\end{array}$ & & & & 1.35 \\
\hline
\end{tabular}

Interaction term: overweight $\times$ sex

(0.63 to 2.89)

(Ref. male)

\section{$1.22^{*}$}

(1.02 to 1.46$)$

$1.54^{\star *}$

Interaction term: obesity $\times$ sex (Ref.

male)

(1.13 to 2.08$)$

\begin{tabular}{lllll} 
Observations & 48865 & 25515 & 23350 & 48865 \\
No of Individuals & 12089 & 6246 & 5843 & 12089 \\
\hline
\end{tabular}

Observations with missing values were dropped (listwise deletion).

Determinants of sick leave days (incidence rate ratios were reported; $95 \% \mathrm{Cl}$ in parentheses).

${ }^{*} \mathrm{P}<0.05,{ }^{* *} \mathrm{P}<0.01,{ }^{* \star *} \mathrm{P}<0.001,+\mathrm{P}<0.10$.

$F E$, fixed effects.

an increase in the probability of sick leave days in women (incidence rate ratio (IRR): $1.2795 \%$ CI 1.02 to 1.57 ), but not in men (IRR $0.85,95 \%$ CI 0.68 to 1.06 ). The corresponding interaction term (sex $\times$ obesity) reached statistical significance $(\mathrm{p}<0.01)$.

Furthermore, sick leave days increased with the onset of disability, increases in age as well as decreases in selfrated health and life satisfaction in the total sample and in both sexes. The outcome measure was not significantly associated with marital status.

Results of conditional FE logistic regressions (outcome measure: long-term absenteeism) are described in table 3. Adjusting for age, marital status, self-rated health, disability and satisfaction with life, conditional FE logistic regressions revealed that transitions from normal weight to overweight were associated with an increase in the probability of long-term absenteeism in women (overweight, OR $1.41,95 \%$ CI 1.08 to 1.85 ), but not in men (overweight, OR 0.84, 95\% CI: 0.65 to 1.09). Gender differences were significant ( $\mathrm{sex} \times$ overweight, $\mathrm{p}<0.01)$.

The probability of long-term absenteeism increased with decreases in self-rated health and the onset of disability in the total sample and in both sexes. The probability of long-term absenteeism decreased with life satisfaction in the total sample and in men, but not in women. Contrarily, the probability of long-term absenteeism was positively associated with increases in age in the total sample and in women, but not in men. 
Table 3 Results of conditional FE logistic regressions (wave 2002, wave 2004, wave 2006, wave 2008, wave 2010 and wave 2012)

\begin{tabular}{|c|c|c|c|c|}
\hline Independent variables & $\begin{array}{l}\text { (1) Long-term } \\
\text { absenteeism: total } \\
\text { sample }\end{array}$ & $\begin{array}{l}\text { (2) Long-term } \\
\text { absenteeism: men }\end{array}$ & $\begin{array}{l}\text { (3) Long-term } \\
\text { absenteeism: } \\
\text { women }\end{array}$ & $\begin{array}{l}\text { (4) Long-term } \\
\text { absenteeism: } \\
\text { total sample with } \\
\text { interaction term }\end{array}$ \\
\hline \multirow[t]{2}{*}{ Age } & $1.02^{* *}$ & $1.02^{\dagger}$ & $1.02^{*}$ & $1.02^{\star \star}$ \\
\hline & (1.01 to 1.04$)$ & (1.00 to 1.05$)$ & (1.00 to 1.05$)$ & (1.01 to 1.04$)$ \\
\hline \multirow{2}{*}{$\begin{array}{l}\text { Married, living together with } \\
\text { spouse (Ref.: others) }\end{array}$} & 1.11 & 1.01 & 1.20 & 1.11 \\
\hline & (0.89 to 1.39 ) & (0.71 to 1.42$)$ & (0.89 to 1.61$)$ & (0.89 to 1.39$)$ \\
\hline \multirow{2}{*}{$\begin{array}{l}\text { Self-rated health (from 1='very } \\
\text { good' to } 5=\text { 'bad') }\end{array}$} & $1.86^{\star \star \star}$ & $1.95^{\star \star \star}$ & $1.78^{\star \star \star}$ & $1.86^{\star \star \star}$ \\
\hline & (1.72 to 2.01 ) & (1.75 to 2.18$)$ & (1.60 to 1.98$)$ & (1.73 to 2.01$)$ \\
\hline \multirow{2}{*}{$\begin{array}{l}\text { Severely disabled (Ref.: not } \\
\text { severely disabled) }\end{array}$} & $2.50^{\star \star \star}$ & $2.38^{\star \star \star}$ & $2.62^{\star \star \star}$ & $2.49^{\star \star \star}$ \\
\hline & (2.02 to 3.09 ) & (1.78 to 3.19 ) & (1.91 to 3.59 ) & (2.01 to 3.09 ) \\
\hline \multirow{2}{*}{$\begin{array}{l}\text { Life satisfaction (from } 0=\text { worst to } \\
10=\text { best) }\end{array}$} & $0.95^{\star \star}$ & $0.92^{\star \star}$ & 0.97 & $0.95^{\star \star}$ \\
\hline & (0.91 to 0.98$)$ & (0.87 to 0.98$)$ & (0.92 to 1.03$)$ & (0.91 to 0.99 ) \\
\hline \multirow{2}{*}{$\begin{array}{l}\text { Underweight (Ref.: normal } \\
\text { weight) }\end{array}$} & $0.57^{\dagger}$ & 0.29 & 0.68 & 0.30 \\
\hline & (0.30 to 1.08$)$ & (0.06 to 1.35$)$ & (0.34 to 1.36$)$ & (0.07 to 1.36$)$ \\
\hline \multirow[t]{2}{*}{ Overweight (Ref.: normal weight) } & 1.08 & 0.84 & $1.41^{*}$ & 0.83 \\
\hline & (0.90 to 1.31$)$ & (0.65 to 1.09$)$ & (1.08 to 1.85$)$ & (0.64 to 1.08$)$ \\
\hline \multirow[t]{2}{*}{ Obesity (Ref.: normal weight) } & 1.05 & 0.77 & $1.49^{\dagger}$ & 0.76 \\
\hline & (0.79 to 1.41$)$ & (0.52 to 1.15$)$ & (0.97 to 2.29$)$ & (0.52 to 1.13$)$ \\
\hline \multirow{2}{*}{$\begin{array}{l}\text { Interaction term: underweight } \times \\
\text { sex (Ref. male) }\end{array}$} & & & & 2.22 \\
\hline & & & & (0.42 to 11.68$)$ \\
\hline $\begin{array}{l}\text { Interaction term: overweight } \times \\
\text { sex (Ref. male) }\end{array}$ & & & & $1.70^{\star \star}$ \\
\hline
\end{tabular}

(1.17 to 2.47$)$

Interaction term: obesity $\times$ sex

$1.95^{\star}$

(Ref. male)

(1.10 to 3.46$)$

\begin{tabular}{|c|c|c|c|c|}
\hline Pseudo R ${ }^{2}$ & 0.08 & 0.09 & 0.08 & 0.08 \\
\hline Observations & 9564 & 4906 & 4658 & 9564 \\
\hline No of Individuals & 2160 & 1115 & 1045 & 2160 \\
\hline
\end{tabular}

Observations with missing values were dropped (listwise deletion).

Determinants of long-term absenteeism (ORs were reported; $(95 \% \mathrm{Cl}$ ) in parentheses).

${ }^{\star} \mathrm{P}<0.05,{ }^{* \star} \mathrm{P}<0.01,{ }^{* \star *} \mathrm{P}<0.001,+\mathrm{P}<0.10$.

FE, fixed effects.

\section{Sensitivity analysis}

Since the results might be affected by attrition bias, sensitivity analyses were conducted to test the robustness of our findings. We re-estimated our models on a sample including only those individuals who were surveyed in each of the six waves (27592 observations with sick leave days as outcome measure; 6139 observations with long-term absenteeism as outcome measure).
With regard to weight categories, the findings were similar to those found in our primary analyses in terms of significance and effect sizes (please see the online supplementary table). In addition, regressions showed that transitions from normal weight to overweight were associated with an increase in the probability of sick leave days in women (IRR $1.19,95 \%$ CI 1.01 to 1.41 ), but not in men (IRR $0.91,95 \%$ CI 0.75 to 1.10 ; with significant interaction term, $\mathrm{p}<0.05)$. 


\section{DISCUSSION}

Based on a nationally representative sample (GSOEP), the aim of the present study was to examine the longitudinal association between obesity and sickness absence in women and in men. Knowledge regarding the longitudinal association between obesity and sickness absence (and the moderating role of sex) is important for implementing strategies to tackle this problem. Data were taken from 2002 to 2012. Adjusting for potential confounders, Poisson FE regression analysis showed that transitions from normal weight to obesity were associated with an increase in sick leave days in women, but not in men (with significant gender differences). Moreover, regression analysis showed that transitions from normal weight to overweight were associated with an increase in the probability of long-term absenteeism in women, but not in men.

According to previous work translating relative effect sizes (eg, IRR and OR) into indices of effect size in public health studies, ${ }^{28}{ }^{29}$ the IRRs and the ORs found in our analyses are classified as small. However, changes in weight from normal weight to overweight were associated with an increase in odds of long-term absenteeism of more than $40 \%$ among women.

The findings of this study generally correspond to those from prior research where overweight and obesity were suggested to be particularly related to long-term absenteeism; whereas no clear evidence for short-term absence was found..$^{78}$ In support of our results, existing studies found gender differences in the relationship between excess weight and absenteeism with a stronger association among women. ${ }^{4} 1030$

As regards long-term absenteeism, our results are to some extent in line with the findings of a previous study conducted among Belgian workers. ${ }^{10}$ The authors found a significant and positive association of both overweight and obesity and high sickness absence in women but not in men. The group of obese women in our study reached only marginal significance $(p<0.10)$ though. In contrast to our results, other studies reported no significant association between BMI class and long-term sickness absence after adjusting for potential confounders for both men and women. ${ }^{931}$

Similar to our findings regarding sick leave days, a study among middle-aged employees in the city of Helsinki also observed a significantly increased risk of sickness absence for obese but not for overweight women, yet only for very short (less than 4 days) spells or spells longer than 14 days. ${ }^{30}$ These findings disagree with the results from a London-based cohort study that reported significant associations between obesity and sick leave for both short and longer spells for both sexes. ${ }^{11}$

While higher rates of female sick leave have been reported in general, the significant interaction effect of sex and BMI on both sick leave days and long-term absenteeism may be further explained by unobserved psychological or psychosocial factors. Overweight and obesity have been proposed to exert a negative effect on one's body image and self-esteem, and this tends to be more pronounced in women, as they may be more affected by the slim ideal compared with men. ${ }^{32}{ }^{33}$ In addition, perceived weight might play a role in the relationship between weight and sickness absence, insofar as negative weight perceptions may lead to higher levels of dissatisfaction and psychological distress, specifically in women. ${ }^{34}$ Furthermore, overweight and obese women are more often targets of weight stigmatisation, weight discrimination and prejudice (eg, laziness, less self-control, work refusal), in particular regarding the workplace setting. ${ }^{35-37}$ This may lead to higher risk of feelings of stress, thereby reducing job resources and increasing job strain. Consequently, they may be more likely to employ poor coping strategies (eg, escaping or avoiding distressing situations) which could eventually result in withdrawal behaviours such as sick leave. ${ }^{31} 34$

Another explanation might be that medical consequences (eg, musculoskeletal diseases, cardiovascular diseases or diabetes) of obesity differ to some extent between women and men. ${ }^{38}{ }^{39}$ Ultimately, these differences in morbidity might lead to differences in sickness absence between women and men. However, future research is needed to investigate this relationship.

Our results suggest a significant association between both the health-related and life satisfaction and illness-related sickness absence. This is in line with findings from previous studies reporting significant effects of selfrated health ${ }^{10} 19$ and morbidity ${ }^{110}$ on sickness absence. Similarly, a relationship between satisfaction with life and sick leave was referred to by previous research. ${ }^{414}$ Concerning marital status, heterogeneous findings have been reported depending on its categorisation, but generally marital status was related to sick leave with a trend towards lower sickness absence among married individuals. ${ }^{43}$ This finding could not be confirmed in our study.

However, it should be stressed that direct comparisons of our results and those of previous studies are difficult because of differences in the measurement of (short-term and long-term) sickness absence, differences in the study design (cross-sectional vs longitudinal), heterogeneity of the study population and the setting.

In total, results of this longitudinal study add to evidence from previous correlational studies, which suggest that obesity is associated with long-term absenteeism cross-sectionally. ${ }^{78}$ Data came from a large nationally representative sample of German individuals (GSOEP). Individuals were observed over a long period (2002-2012). By using FE regressions, the problem of unobserved heterogeneity was diminished. ${ }^{25}$

Because in Germany, sick pay is shortened after 6 weeks and not paid any longer by the employer but by a thirdparty payer (eg, health insurance), and a different medical certificate has to be provided, it is expected that employees will quite accurately remember their sick leave spells. Hence, this indicator should be less prone to measurement error. ${ }^{44}$ As regards sick leave days, we cannot dismiss the possibility of a recall bias. However, 
it has been shown that self-reported sick leave can be employed as a proxy measure when administrative data are not available. ${ }^{45}$

The self-rated BMI was used to classify obesity. As individuals tend to overestimate height and underestimate weight, ${ }^{46}$ the BMI might be biased downwards. However, under the assumption that this bias is constant within individuals over time, this does not bias the FE estimates. In addition, a prior study investigating the predictive performance of different body weight measures on sickness absence found that self-reported BMI performed equally well as measured BMI. ${ }^{47}$ Moreover, it is worth emphasising that panel attrition might bias the FE estimates. However, it has been shown that panel attrition is quite low in the GSOEP. ${ }^{15}$ In addition, the sensitivity analysis conducted indicates that attrition bias might be rather small. In addition, long-term absenteeism and sick leave days were quantified retrospectively. Hence, we cannot rule out that the outcome measures affect BMI change (endogeneity bias). Thus, future studies (eg, based on panel instrumental variable procedures) are needed to overcome these problems.

As regards generalisability, it should be noted that results of $\mathrm{FE}$ regressions are often interpreted as average treatment effect on the treated. ${ }^{48}$ Consequently, our findings are generalisable to individuals in the population who change their sickness absence behaviour in Germany over time. As already argued by Brüderl and Ludwig, ${ }^{48}$ this is not a limitation of FE estimates. It simply reflects the fact that only a small proportion of individuals in the population changed their sickness absence behaviour.

To conclude, our findings highlight the longitudinal association between excess weight and workplace absenteeism. Effective interventions to treat excess weight might also be a promising strategy to reduce sickness absence in women.

Acknowledgements The data used in this publication were made available to us by the German Socio-Economic Panel Study (GSOEP) at the German Institute for Economic Research (DIW), Berlin.

Contributors KCR, H-HK and AH made substantial contributions to conception and design of the study, the analysis and interpretation of data and drafted the manuscript. All authors read and approved the final manuscript.

Funding This research received no specific grant from any funding agency in the public, commercial or not-for-profit sectors.

\section{Competing interests None declared.}

Patient consent Obtained.

Ethics approval The German Council of Science and Humanities

(Wissenschaftsrat) evaluated the German Socio-Economic Panel (GSOEP) at the Deutsches Institut für Wirtschaftsforschung, (DIW), Berlin. The German Council of Science and Humanities approved the GSOEP. The GSOEP is in accordance with the Declaration of Helsinki as revised in 2008. Informed consent was obtained from all participants.

Provenance and peer review Not commissioned; externally peer reviewed.

Data sharing statement GSOEP data access must comply with high-security standards for maintaining confidentiality and protecting personal privacy. The data are also subject to regulations limiting their use to scientific purposes, that is, they are only made available to the scientific community (in German language only). After conclusion of a data distribution contract with DIW Berlin, the data of every new wave will be available on request either via personalised encrypted download or via certified mail on a DVD. Please visit the website for further information (https://www.diw.de/en/diw_02.c.238237.en/conditions.html).

Open Access This is an Open Access article distributed in accordance with the Creative Commons Attribution Non Commercial (CC BY-NC 4.0) license, which permits others to distribute, remix, adapt, build upon this work non-commercially, and license their derivative works on different terms, provided the original work is properly cited and the use is non-commercial. See: http://creativecommons.org/ licenses/by-nc/4.0/

(c) Article author(s) (or their employer(s) unless otherwise stated in the text of the article) 2018. All rights reserved. No commercial use is permitted unless otherwise expressly granted.

\section{REFERENCES}

1. Finucane MM, Stevens GA, Cowan MJ, et al. National, regional, and global trends in body-mass index since 1980: systematic analysis of health examination surveys and epidemiological studies with 960 country-years and 9.1 million participants. Lancet 2011;377:557-67.

2. Explained ES. Overweight and obesity - BMI statistics 2017. http:// ec.europa.eu/eurostat/statistics-explained/index.php/Overweight_ and_obesity_-_BMI_statistics (accessed 26 Jul 2017).

3. Mensink GB, Schienkiewitz A, Haftenberger M, et al. [Overweight and obesity in Germany: results of the German Health Interview and Examination Survey for Adults (DEGS1)]. Bundesgesundheitsblatt Gesundheitsforschung Gesundheitsschutz 2013:56:786-94.

4. Lehnert T, Stuhldreher N, Streltchenia P, et al. Sick leave days and costs associated with overweight and obesity in Germany. J Occup Environ Med 2014;56:20-7.

5. Wolfenstetter SB, Menn P, Holle R, et al. Body weight changes and outpatient medical care utilisation: Results of the MONICA/KORA cohorts S3/F3 and S4/F4. Psychosoc Med 2012;9.

6. Dee A, Kearns K, O'Neill C, et al. The direct and indirect costs of both overweight and obesity: a systematic review. BMC Res Notes 2014;7:242

7. van Duijvenbode DC, Hoozemans MJ, van Poppel MN, et al. The relationship between overweight and obesity, and sick leave: a systematic review. Int J Obes 2009;33:807-16.

8. Neovius K, Johansson K, Kark M, et al. Obesity status and sick leave: a systematic review. Obes Rev 2009;10:17-27.

9. Harvey SB, Glozier N, Carlton O, et al. Obesity and sickness absence: results from the CHAP study. Occup Med 2010;60:362-8.

10. Janssens $\mathrm{H}$, Clays $\mathrm{E}$, Kittel $\mathrm{F}$, et al. The association between body mass index class, sickness absence, and presenteeism. J Occup Environ Med 2012;54:604-9.

11. Ferrie JE, Head J, Shipley MJ, Shiplea KJ, et al. BMI, obesity, and sickness absence in the Whitehall II study. Obesity 2007;15:1554-64.

12. Wagner G, Frick J, Schupp J. The German Socio-Economic Panel Study (SOEP) - scope, evolution and enhancements. Schmollers Jahrbuch: Journal of Applied Social Science Studies / Zeitschrift für Wirtschafts- und Sozialwissenschaften 2007;127:139-69.

13. Schoeni RF, Stafford F, McGonagle KA, et al. Response rates in national panel surveys. Ann Am Acad Pol Soc Sci 2013;645:60-87.

14. Kroh M, Kühne S, Siegers R, et al. SOEP-Core-Documentation of sample sizes and panel attrition (1984 until 2016): SOEP Survey Papers, 2018.

15. Lipps O. Attrition of Households and Individuals in Panel Surveys, 2009.

16. Wagner GG, Frick JR, Schupp J. The German Socio-Economic Panel study (SOEP)-evolution, scope and enhancements. Schmollers Jahrbuch, 2007:127 139-70.

17. Jebb SA, Johnstone AM, Warren J, et al. Key Methodologies in Obesity Research and Practice: Obesity: John Wiley \& Sons, Ltd 2009:45-75.

18. World Health Organization (WHO). Obesity: Preventing and Managing the Global Epidemic Technical Report Series. Geneva, Switzerland: World Health Organization, 2000.

19. Laaksonen M, Piha K, Sarlio-Lähteenkorva S. Relative weight and sickness absence. Obesity 2007;15:465-72.

20. Voss M, Floderus B, Diderichsen F, Physical DF. Physical, psychosocial, and organisational factors relative to sickness absence: a study based on Sweden Post. Occup Environ Med 2001;58:178-84.

21. Johnson RJ, Wolinsky FD. The structure of health status among older adults: disease, disability, functional limitation, and perceived health. $J$ Health Soc Behav 1993;34:105-21.

22. Verbrugge LM, Jette AM. The disablement process. Soc Sci Med 1994;38:1-14. 
23. Taloyan M, Aronsson G, Leineweber C, et al. Sickness presenteeism predicts suboptimal self-rated health and sickness absence: a nationally representative study of the Swedish working population. PLoS One 2012;7:e44721.

24. Cameron AC, Trivedi PK. Microeconometrics: Methods and Applications. New York: Cambridge University Press, 2005.

25. Brüderl J, Ludwig V. Fixed-effects panel regression. The Sage Handbook of Regression Analysis and Causal Inference. Wolf C. Los Angeles: SAGE, 2015:327-57.

26. Hausman JA. Specification tests in econometrics. Econometrica 1978;46:1251-71.

27. Stock JH, Watson MW. Heteroskedasticity-robust standard errors for fixed effects panel data regression. Econometrica 2008;76:155-74.

28. Chen $\mathrm{H}$, Cohen $\mathrm{P}$, Chen $\mathrm{S}$. How big is a big odds ratio? interpreting the magnitudes of odds ratios in epidemiological studies. Commun Stat Simul Comput 2010;39:860-4.

29. Olivier J, May WL, Bell ML. Relative effect sizes for measures of risk. Commun Stat Theory Methods 2017;46:6774-81.

30. Roos E, Laaksonen M, Rahkonen O, et al. Weight change and sickness absence--a prospective study among middle-aged employees. Eur J Public Health 2015;25:263-7.

31. Nigatu YT, Roelen CA, Reijneveld SA, et al. Overweight and distress have a joint association with long-term sickness absence among Dutch employees. J Occup Environ Med 2015;57:52-7.

32. Friedman KE, Reichmann SK, Costanzo PR, et al. Body image partially mediates the relationship between obesity and psychological distress. Obes Res 2002;10:33-41.

33. McKinley NM. Longitudinal gender differences in objectified body consciousness and weight-related attitudes and behaviors: cultural and developmental contexts in the transition from college. Sex Roles 2006;54:159-.

34. Lam CK, Huang X, Chiu WCK. Mind over body? The combined effect of objective body weight, perceived body weight, and gender on Illness-related absenteeism. Sex Roles 2010;63:277-89.

35. Giel KE, Thiel A, Teufel M, et al. Weight bias in work settings - a qualitative review. Obes Facts 2010;3:33-40.

36. Puhl RM, Andreyeva T, Brownell KD. Perceptions of weight discrimination: prevalence and comparison to race and gender discrimination in America. Int J Obes 2008;32:992-1000.
37. Giel KE, Zipfel S, Alizadeh M, et al. Stigmatization of obese individuals by human resource professionals: an experimental study. BMC Public Health 2012;12:525-25.

38. Kim IH, Chun H, Kwon JW. Gender differences in the effect of obesity on chronic diseases among the elderly Koreans. J Korean Med Sci 2011;26:250-7.

39. Mauvais-Jarvis F. Epidemiology of Gender Differences in Diabetes and Obesity. Mauvais-Jarvis F, ed. Sex and Gender Factors Affecting Metabolic Homeostasis, Diabetes and Obesity. Cham: Springer International Publishing, 2017:3-8.

40. Robroek SJ, van den Berg TI, Plat JF, et al. The role of obesity and lifestyle behaviours in a productive workforce. Occup Environ Med 2011;68:134-9.

41. Straume LV, Vitters $ø$ J. Well-being at work: some differences between life satisfaction and personal growth as predictors of subjective health and sick-leave. J Happiness Stud 2015;16:149-68.

42. Rolli Salathé C, Melloh M, Mannion AF, et al. Resources for preventing sickness absence due to low back pain. Occup Med 2012;62:273-80.

43. Allebeck P, Mastekaasa A. Chapter 5. Risk factors for sick leave general studies. Scand J Public Health 2004;32:49-108.

44. Ziebarth NR. Long-term absenteeism and moral hazard-Evidence from a natural experiment. Labour Econ 2013;24:277-92.

45. Short ME, Goetzel RZ, Pei X, et al. How accurate are self-reports? Analysis of self-reported health care utilization and absence when compared with administrative data. J Occup Environ Med 2009;51:786-96.

46. Connor Gorber S, Tremblay M, Moher D, et al. A comparison of direct vs. self-report measures for assessing height, weight and body mass index: a systematic review. Obes Rev 2007;8:307-26.

47. Korpela K, Roos E, Lallukka T, et al. Different measures of body weight as predictors of sickness absence. Scand J Public Health 2013;41:25-31.

48. Brüderl J, Ludwig V. Fixed-effects panel regression. Wolf C, ed. The Sage Handbook of Regression Analysis and Causal Inference. Los Angeles: SAGE, 2015:327-57. 